\title{
Metabolic responses to selective $\beta$-adrenergic stimulation in man
}

\author{
R. GOLDBERG \\ B.Sc., M.B., B.Ch. \\ B. I. JoFFE \\ M.R.C.P. \\ I. BERSOHN* \\ B.Sc., M.B., B.Ch., F.R.C.Path. \\ M. VAN As \\ B.Sc. \\ L. KRUT \\ M.D. \\ H. C. Seftel \\ B.Sc., M.B., B.Ch., Dip.Med. \\ Carbohydrate and Lipid Metabolism Research Unit, Department of Medicine, Witwatersrand \\ University, and *South African Institute for Medical Research, Johannesburg, South Africa
}

\section{Summary}

The responses of plasma free fatty acid, glucose, lactate, insulin and growth hormone to intravenous administration of the predominantly $\beta-2$ stimulant, salbutamol, were studied in nine normal subjects. Four subjects received the predominantly $\beta-1$ blocking agent, practolol, together with salbutamol.

Salbutamol produced a marked rise in free fatty acid levels and there was also an appreciable increase in insulin values; lactate levels rose moderately and glucose values increased slightly; growth hormone levels were not affected. Practolol did not alter the free fatty acid response; it diminished but did not appear to abolish the insulin response, and it appeared to suppress the lactate and glucose rises.

Tentative proposals are made regarding the nature of the $\beta$-receptor subtypes responsible for mediating these effects; most definite is the suggestion that lipolysis is subserved by $\beta-2$ receptors. Possible clinical implications are briefly discussed.

\section{Introduction}

$\beta$-adrenergic stimulants can be divided into two types. The first, which is best exemplified by isoprenaline (isoproterenol), are non-selective and, according to the classification proposed by Lands and co-workers (1967), have both $\beta$-1 (cardiac stimulant) and $\beta-2$ (bronchodilator and vasodilator) effects. Isoprenaline also has a number of metabolic actions such as stimulation of free fatty acid and insulin release (Porte, 1967), but it is uncertain whether these are mediated by $\beta-1$ or $\beta-2$ receptors, at least in man.

Correspondence: Professor H. C. Seftel, Department of Medicine, Medical School, Hospital Street, Hospital Hill, Johannesburg, South Africa.
Secondly, there are the relatively selective $\beta$ adrenergic agents such as salbutamol, hexaprenaline, terbutaline and fenoterol, which are predominantly $\beta-2$ stimulants and which have largely replaced isoprenaline in the treatment of bronchial asthma. Little is known about their metabolic effects in man, and in this paper we report the responses of plasma insulin, growth hormone, free fatty acid, glucose and lactate to intravenous administration of salbutamol. In addition, by administering salbutamol together with practolol (an agent which selectively blocks $\beta$-1 receptors), we have attempted to eliminate the $\beta-1$ effect of salbutamol and thereby to study the effects of 'pure' $\beta-2$ stimulation. This, it was thought, would help to define the metabolic effects of $\beta$-adrenergic stimulation in terms of the two $\beta$-receptor subtypes.

\section{Subjects and methods}

Nine healthy white males aged 19-45 years volunteered for the study, the nature of which was fully explained. All were within $10 \%$ of ideal body weight (Ciba-Geigy Scientific Tables, 1970) except one who was $15 \%$ in excess of this weight, but his metabolic responses were similar to those of the rest of the group.

Each subject was studied twice, at an interval of 1 week, and in random order. On one occasion the effects of salbutamol were studied in all nine subjects. On another, five subjects underwent a similar procedure except that saline was substituted for salbutamol. The four remaining subjects received salbut amol but in addition they were pretreated with $200 \mathrm{mg}$ oral practolol at 10 p.m. on the day before the test and again at 6 a.m. on the day of the investigation which began at 8 a.m. 
All studies were done after a $12-\mathrm{hr}$ fast and at bedrest. A catheter was inserted into an antecubital vein and kept patent by a slow saline infusion. Half an hour later two blood samples were drawn, $10 \mathrm{~min}$ apart, to obtain baseline measurements. Fifty $\mu \mathrm{g}$ of salbutamol as sulphate in $5 \mathrm{ml}$ of saline (or the same volume of saline only) was then infused as a bolus over a period of $2 \mathrm{~min}$. Blood was sampled at 2, 3, 4, $5,10,15$ and $30 \mathrm{~min}$ after completing the infusion. Immediately after the withdrawal of the $30-\mathrm{min}$ sample, a second bolus containing $100 \mu \mathrm{g}$ of salbutamol (or saline) was infused and blood sampled at the same times. The procedure was then repeated with $150 \mu \mathrm{g}$ salbutamol. Heart rate was recorded at rest and at 2, 5, 10, 15 and $30 \mathrm{~min}$ after each dose, and the subjects were asked to report whether they experienced palpitations.

Blood samples were collected in heparinized tubes and kept in ice until centrifuged within the next hour. Aliquots of plasma were taken for measurement of free fatty acids by a modified method of Dole (1956), insulin by the radioimmunoassay method of Morgan and Lazarow (1963), growth hormone by the radioimmunoassay method of Hartog et al. (1964), lactate by an enzymatic method (Boehringer Test Combination), and glucose by the Auto Analyzer neocuproine method (Brown, 1961).

The findings were expressed as percentage change from basal values. The mean of the two initial baseline measurements constituted the basal level for changes noted after administering $50 \mu \mathrm{g}$ salbutamol. The levels measured $30 \mathrm{~min}$ after giving 50 and $100 \mu \mathrm{g}$ salbutamol constituted the basal values for changes observed after infusing 100 and $150 \mu \mathrm{g}$ salbutamol, respectively; this was done because after each dose of salbutamol the levels of most of the substances measured rose and then tended to fall back, but not to return, to the baseline values by the end of the 30-min sampling period.

Finally, six of the nine subjects who received the three doses of salbutamol were also infused with this substance at the rate of $5 \mu \mathrm{g} / \mathrm{min}$ for $30 \mathrm{~min}$. Blood was sampled for free fatty acid estimation during and after the infusion which was started shortly after the observations on the effects of the $150 \mu \mathrm{g}$ bolus had been completed.

Student's ' $t$ ' test was used for most of the statistical analyses. Dose-response relationships were determined by analysis of both peak values and calculated areas under the curves.

\section{Results}

No significant changes occurred after infusing saline, and pretreatment with oral practolol had no effect on the initial baseline values of any of the substances studied. The following description is confined to the effects of salbutamol alone and of salbutamol with practolol pretreatment.

\section{Heart rate (Fig. 1)}

Heart rate increased after each dose of salbutamol. The increase produced by the $150 \mu \mathrm{g}$ bolus was greater than that observed with the $50 \mu \mathrm{g}(P<0.001)$ and $100 \mu \mathrm{g}(P<0.01)$ doses. With practolol pretreatment the rise was inhibited at all times, and only at $2 \mathrm{~min}$ after the $150 \mu \mathrm{g}$ bolus was a significant increase in rate detectable $(P<0.05)$.

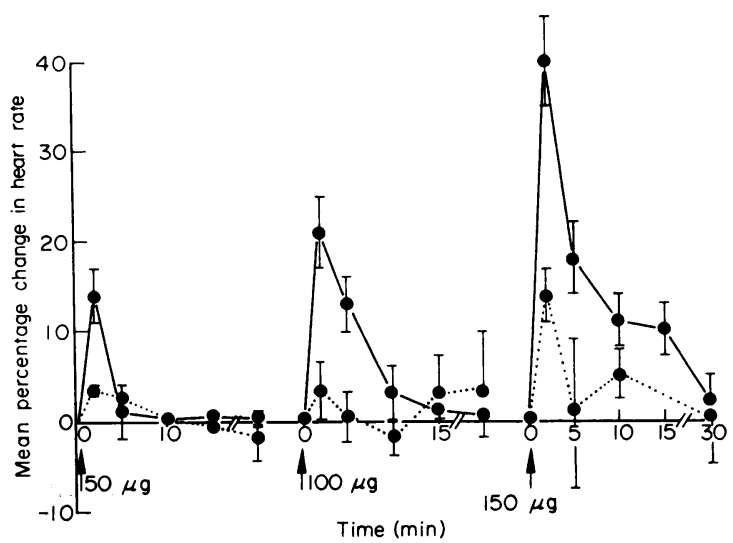

Fig. 1. Response of heart rate to intravenous salbutamol with and without oral practolol. Solid line, salbutamol; broken line, salbutamol plus practolol.

\section{Free fatty acids}

After each dose of salbutamol plasma free fatty acid levels rose promptly and markedly, reaching a peak at the fourth or fifth minute and then falling gradually towards the baseline (Fig. 2). The mean peak values after 50,100 and $150 \mu \mathrm{g}$ of salbutamol were 1033,1282 and $1214 \mu \mathrm{Eq} / \mathrm{l}$, the maximum mean percentage changes being 146, 205 and 161 respectively. Pretreatment with practolol did not alter this response.

The effects of infusing salbutamol for $\mathbf{3 0} \mathrm{min}$ are shown in Fig. 3. All six subjects again exhibited a prompt and marked elevation in fatty acid levels. These tended to reach a peak at 15 min which was then maintained during the remainder of the infusion. Maximum values ranged from 950 to $1520 \mu \mathrm{Eq} / 1$.

\section{Insulin (Fig. 4)}

Each bolus of salbutamol produced a rapid rise in plasma insulin levels which reached a peak at the fourth or fifth minute and then gradually returned to the baseline. Maximum mean percentage changes after the three doses were 59,135 and 94 , the mean 


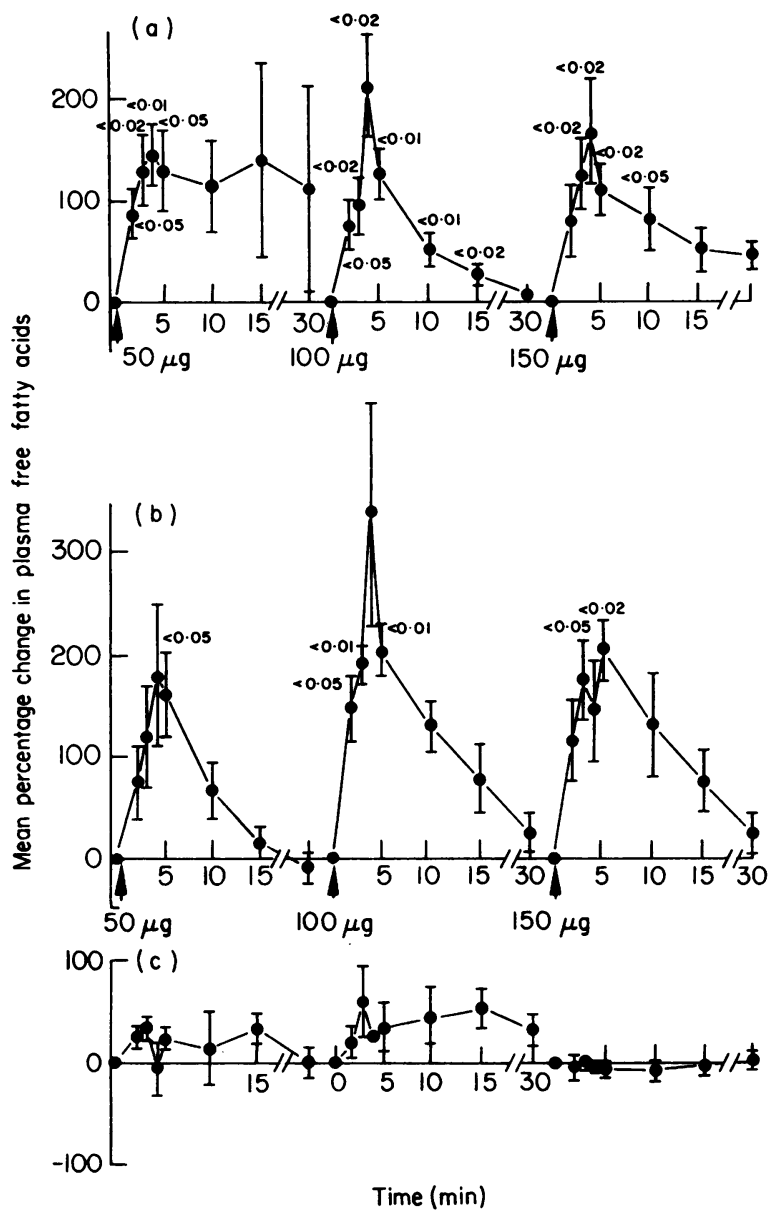

FIG. 2. Response of plasma free fatty acids to intravenous salbutamol with and without oral practolol, and in saline controls. (a) Salbutamol intravenous (nine subjects); (b) salbutamol intravenous plus pretreatment with oral practolol (four subjects); (c) saline control (five subjects).

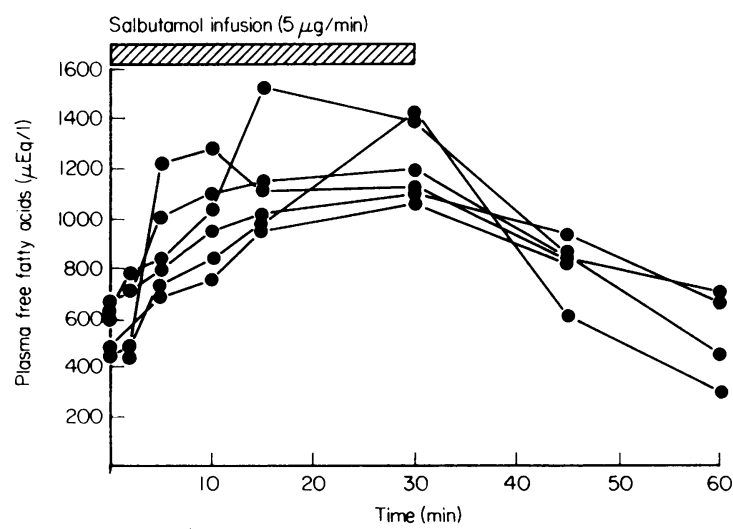

Fig. 3. Plasma free fatty acid response to salbutamol infusion.

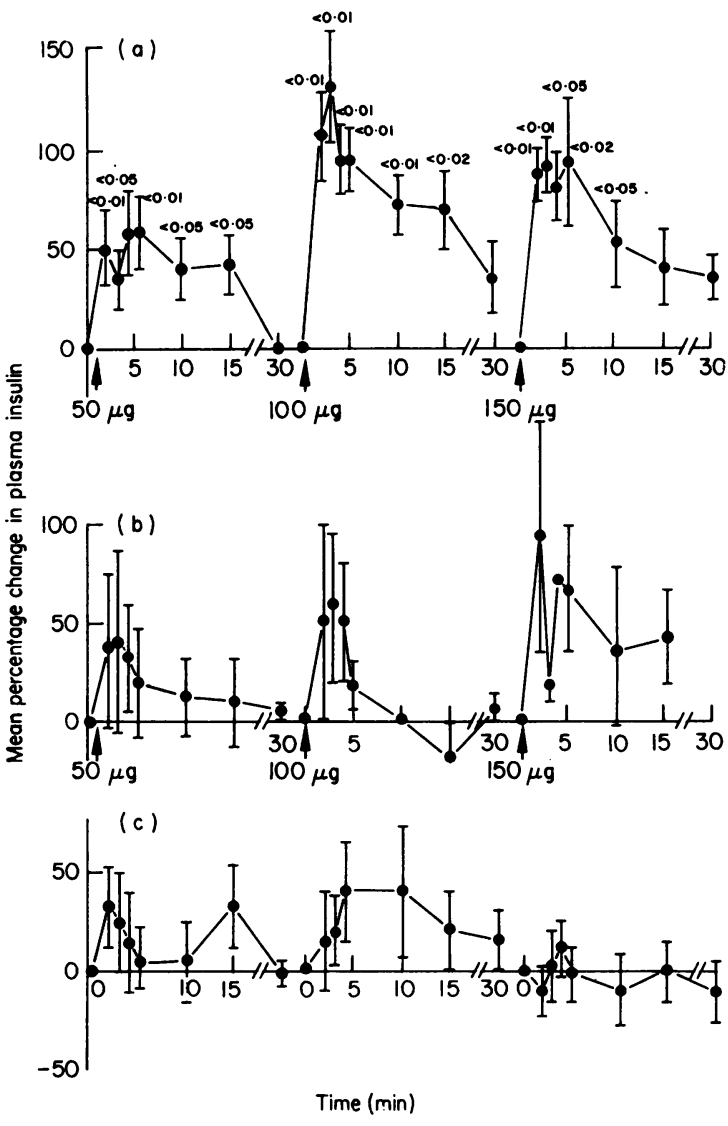

FIG. 4. Response of plasma insulin to intravenous salbutamol with and without oral practolol, and in saline controls. (a) Salbutamol intravenous (nine subjects); (b) salbutamol intravenous plus pretreatment with oral practolol (four subjects); (c) saline control (five subjects).

peak levels being 16,20 and $25 \mu \mathrm{U} / \mathrm{ml}$, respectively. With practolol pretreatment the changes were not significant.

\section{Lactate (Fig. 5)}

Plasma lactate levels rose after the 100 and $150 \mu \mathrm{g}$ doses of salbutamol, reaching a peak at $15 \mathrm{~min}$ and then falling slowly. Maximum mean percentage changes were 29 and 39 , and mean peak values $9 \cdot 2$ and $12.2 \mathrm{mg} / 100 \mathrm{ml}$ respectively. Although a dose response relationship was suggested this was not confirmed statistically. In subjects pretreated with practolol no significant rise in lactate levels occurred.

\section{Glucose (Fig. 6)}

Small but significant rises were noted between 4 and 15 min after each bolus. The maximum mean 


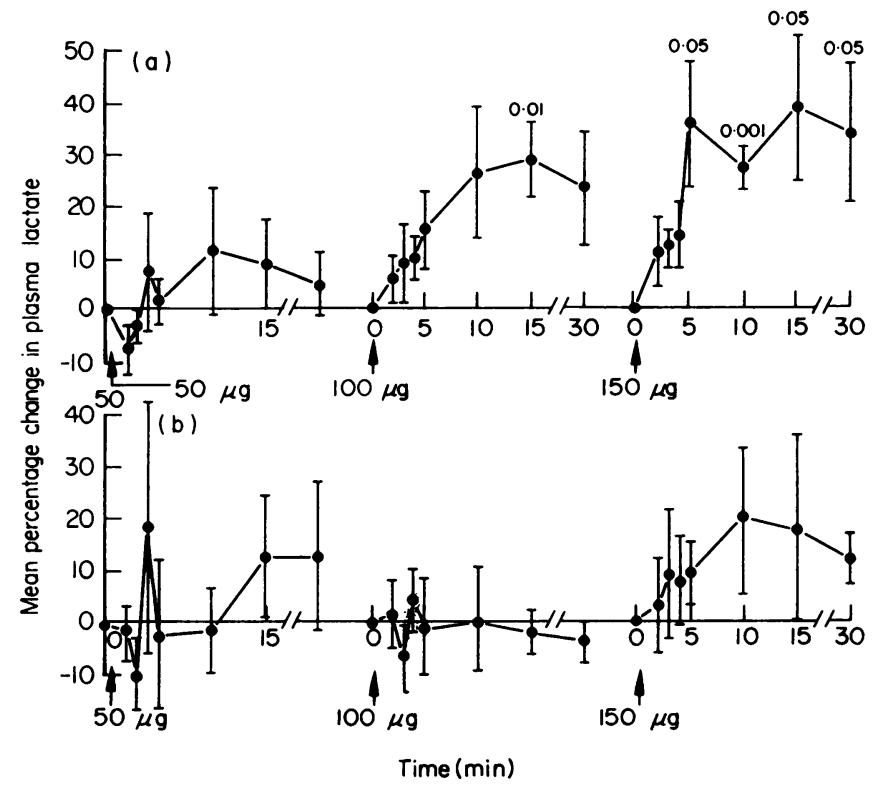

Fig. 5. Plasma lactate response to intravenous salbutamol with and without oral practolol. (a) Salbutamol intravenous (nine subjects); (b) salbutamol intravenous plus pretreatment with oral practolol (four subjects).

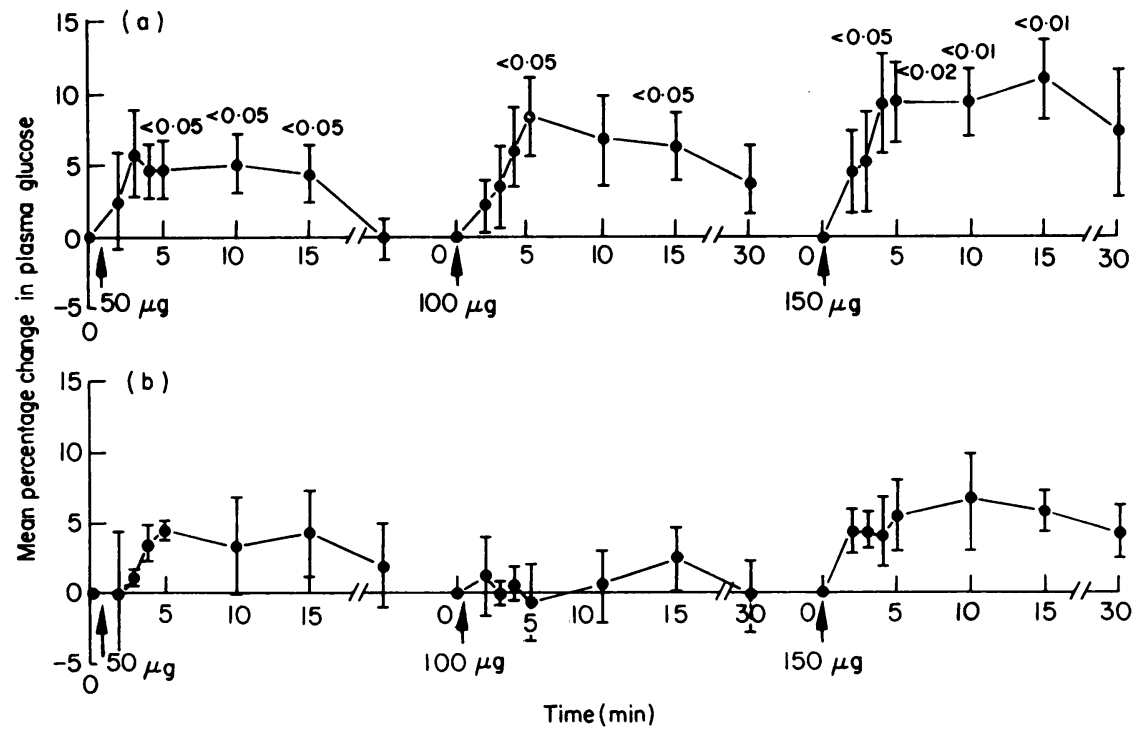

Fig. 6. Plasma glucose response to intravenous salbutamol with and without oral practolol. (a) Salbutamol intravenous (nine subjects); (b) salbutamol intravenous plus pretreatment with oral practolol (four subjects). 
percentage changes were 6,8 and 11 , and the mean peak levels 97,101 and $106 \mathrm{mg} / 100 \mathrm{ml}$ respectively. As in the case of lactate, an apparent dose-response relationship was not demonstrable statistically. The glucose levels did not rise significantly in subjects pretreated with practolol.

\section{Growth hormone}

Baseline levels ranged from 0.8 to $3.3 \mathrm{ng} / \mathrm{ml}$. Neither salbutamol alone nor salbutamol with practolol pretreatment produced any significant change.

\section{Discussion}

This study has shown that in man the metabolic effects of intravenously administered salbutamol are similar to those of the non-selective $\beta$-adrenergic agent, isoprenaline (Porte, 1967; Imura et al., 1971). Salbutamol stimulated the release of free fatty acids and insulin, produced a moderate rise in plasma lactate levels and a small increase in glucose values, and had no detectable effect on growth hormone levels. In some instances a dose-response effect was suggested but could not be confirmed statistically, indicating that the effects of the initial $50 \mu \mathrm{g}$ bolus were maximal or nearly so. This was unexpected since in preliminary experiments doses less than 50 $\mu \mathrm{g}$, e.g. $25 \mu \mathrm{g}$, produced little or no cardiac or metabolic response except a moderate increase in free fatty acid levels.

Less clear are the results of our attempts to define the metabolic effects in terms of the two $\beta$-receptor subtypes. Interpretation of the findings is subject to several reservations. In the first place, although there is a good deal of evidence for the existence of the subtypes postulated by Lands and co-workers (1967), the matter is far from proven. Critical reviews (Furchgott, 1970; Jenkinson, 1973) have shown that the subject is one of considerable complexity, and that the different $\beta$-adrenergic responses may be explained in ways other than that suggested by the subtype hypothesis. It should also be remembered that much of the work, including that of Lands et al. (1967) has been done on a variety of animal preparations and the findings are not necessarily applicable to man (Ellis, 1970). Secondly, even assuming that the subtypes exist in man, there is at least one limitation in the type of experimental design employed here. We attempted to eliminate the $\beta-1$ effect of salbutamol, and hence to create a situation of 'pure' $\beta-2$ stimulation, by pretreatment with practolol. However, our criterion for blockade of the $\beta-1$ receptor was inhibition of cardiac stimulation, and there is no certainty that metabolic responses mediated by this receptor were also blocked. The following analysis is therefore tentative and requires confirmation.
Most definite, and also of most interest, is the inference to be drawn from the free fatty acid ressponses. Salbutamol, a predominantly $\beta-2$ stimulant, exhibited a marked lipolytic effect which was not altered by $\beta-1$ blockade. This suggests that lipolysis in man is mediated by $\beta-2$ receptors, which is at variance with the conclusion of Lands et al. (1967) based on in vitro animal studies that the $\beta-1$ subtype is responsible. However, other animal experiments have been interpreted as indicating that lipolysis is a $\beta-2$ effect (Himms-Hagen, 1970). This was also the conclusion of Carlström and Westling's (1970) human study of the metabolic, circulatory and respiratory effects of the predominantly $\beta$-2stimulant, terbutaline.

The appreciable insulin response to salbutamol alone suggests that release of the hormone is mediated by $\beta-2$ receptors, which is in keeping with the findings of Loubatières and co-workers (1971) in dogs. However, the response was blunted by practolol, indicating that insulin release may be a $\beta-1$ effect. On the other hand, the response did not appear to be completely abolished by $\beta-1$ blockade, so that it is possible that both $\beta-1$ and $\beta-2$ receptors are involved. At all events, release of the hormone was not due to the rise in plasma glucose which was slight and tended to occur after the insulin rise.

The plasma lactate and glucose elevations produced by salbutamol were moderate or mild, suggesting that they might be the result of its relatively minor $\beta-1$ action, and this is supported by their suppression by practolol. The lactate and glucose responses are probably due, at least in part, to stimulation of glycogenolysis in muscle and liver respectively. Most animal studies have indicated that these metabolic functions are mediated by $\beta$-receptors (Brody and McNeill, 1970; Hornbrook, 1970), and one group of investigators has suggested that in dogs the $\beta-2$ subtype is involved (Arnold et al., 1968).

Salbutamol, both with and without practolol pretreatment, had no detectable effect on plasma growth hormone levels. We are unaware of other studies of the effects of selective $\beta$-adrenergic agents on growth hormone in man or animals. Imura and co-workers (1971) found that isoprenaline had no effect on fasting levels of the hormone in man. However, they observed that the drug inhibited the rise in growth hormone induced by the non-selective $\beta$-blocking agent, propranolol.

These findings may have clinical implications. In recent years salbutamol and other relatively selective $\beta$-adrenergic drugs have increasingly replaced isoprenaline in bronchodilator aerosols, largely because they are believed to be safer so far as the cardiovascular system is concerned. Intravenous forms of these agents are now on trial (Harris, 1973), or are 
already in general use (e.g. hexaprenaline in South Africa) in patients with severe asthma who are not amenable or are unresponsive to aerosol therapy. This practice, however, may be less safe. On the basis of studies in myocardial infarction some believe that the combination of high plasma free fatty acid concentrations (more than $1200 \mu \mathrm{Eq} / \mathrm{l}$ ), high catecholamine levels and hypoxia is responsible for the development of dangerous ventricular arrhythmias and decreased myocardial contractility (Oliver, 1972). In severe bronchial asthma it is probable that a similar pattern of metabolic abnormalities exists, the myocardium is also under strain and sudden cardiac deaths are well documented (Bates, Macklem and Christie, 1971). There may, therefore, be hazards in treating this condition with infusions of salbutamol or other $\beta$-adrenergic agents, all of which appear able to increase plasma free fatty acid levels markedly and, in greater or lesser measure, to stimulate the heart. Their use may be especially risky in combination with intravenous aminophylline which is also lipolytic and a cardiac stimulant (Robison, Butcher and Sutherland, 1968). We are unaware of concrete clinical evidence for the dangers suggested and there are divergent views regarding the cardiac toxicity of high plasma free fatty acid levels (Nelson, 1970; Opie, 1972). Nevertheless, it would appear prudent at the present time to be circumspect and cautious in the use of parenteral $\beta$-adrenergic agents in severe bronchial asthma.

\section{Acknowledgments}

Thanks are expressed to the South African Medical Research Council which supported this work, and to B.D.H. South Africa (Pty) Limited for supplies of intravenous salbutamol. Thanks are also due to the Director of The South African Institute for Medical Research for providing facilities for this investigation.

\section{References}

Arnold, A., McAuliff, J.P., Colella, D.F., O'Connor, W.V. \& Brown, T.G. (1968) The $\beta-2$ receptor mediated glycogenolytic responses to catecholamines in the dog. Archives Internationales de Pharmacodynamie et de Thérapie, 176, 451.

Bates, D.V., Macklem, P.T. \& Christie, R.V. (1971) In: Respiratory Function in Disease, p. 131. W. B. Saunders Company: Philadelphia.

Brody, T.M. \& MCNeill, J.H. (1970) Adrenergic receptors for metabolic responses in skeletal and smooth muscles. Federation Proceedings, 29, 1375.
BRown, M.E. (1961) Ultramicro sugar determinations using 2,9-dimethyl-1,10-phenanthroline hydrochloride (neocuproine). Diabetes, 10, 60.

Carlström, S. \& Westling, H. (1970) Metabolic, circulatory and respiratory effects of a new sympathomimetic $\beta$ receptor-stimulating agent, terbutaline, compared with those of orciprenaline. Acta medica scandinavica, Supplement, 512, 33.

Documenta Geigy (1970) Scientific Tables, 7th edition. (Ed. by K. Diem and C. Lentner), p. 72. Ciba-Geigy Limited: Basle, Switzerland.

Dole, V.P. (1956) A relation between non-esterified fatty acids in plasma and the metabolism of glucose. Journal of Clinical Investigation, 35, 150.

Ellis, S. (1970) Adrenergic receptors mediating metabolic responses-introductory remarks. Federation Proceedings, 29, 1350.

FuRCHGOTT, R.F. (1970) Pharmacological characteristics of adrenergic receptors. Federation Proceedings, 29, 1352.

HARRIS, D.M. (1973) Personal communication from Allen \& Hanburys Research Limited, U.K.

Hartog, M., GaAfar, M A., Meisser, B. \& Fraser, R. (1964) Immunoassay of serum growth hormone in acromegalic patients. British Medical Journal, ii, 1229.

Himms-HAGEN, J. (1970) Adrenergic receptors for metabolic responses in adipose tissue. Federation Proceedings, 29, 1388.

HoRNBROOK, K.R. (1970) Adrenergic receptors for metabolic responses in the liver. Federation Proceedings, 29, 1381.

Imura, H., Kato, Y., Ikeda, M., MoRimoto, M. \& Yawata, M. (1971) Effect of adrenergic-blocking or -stimulating agents on plasma growth hormone, immunoreactive insulin and blood free fatty acid levels in man. Journal of Clinical Investigation, 50, 1069.

JENKINSON, D.H. (1973) Classification and properties of peripheral adrenergic receptors. British Medical Bulletin, 29, 142.

Lands, A.M., Arnold, A., McAuliff, J.P., Luduena, F.P. \& BRown, T.G. (1967) Differentiation of receptor systems activated by sympathomimetic amines. Nature, 214, 597.

Loubatières, A., Mariani, M.M., Sorel, G. \& Savi, L. (1971) The action of $\beta$-adrenergic blocking and stimulating agents on insulin secretion. Characterization of the type of $\beta$-receptor. Diabetologia, 7, 127.

Morgan, C.R. \& Lazarow, A. (1963) Immunoassay of insulin: two antibody system. Diabetes, 12, 115.

Nelson, P.G. (1970) Effect of heparin on serum free-fattyacids, plasma catecholamines, and the incidence of arrhythmias following acute myocardial infarction. British Medical Journal, iii, 735.

Oliver, M.F. (1972) Metabolic response during impending myocardial infarction-clinical implications. Circulation, 45, 491.

OPIE, L.H. (1972) Metabolic response during impending myocardial infarction-relevance of studies of glucose and fatty acid metabolism in animals. Circulation, 45, 483.

PORTE, D. (1967) Beta adrenergic stimulation of insulin release in man. Diabetes, 16, 150.

Robison, G.A., Butcher, R.W. \& Sutherland, E.W. (1968) Cyclic AMP. Annual Review of Biochemistry, 37, 149. 